\title{
LA CARGA DE LA PRUEBA EN EL CONTENCIOSO ADMINISTRATIVO AMBIENTAL CHILENO: NOTAS A PROPÓSITO DE LA LEY DE TRIBUNALES AMBIENTALES
}

\author{
THE BURDEN OF PROOF IN THE CHILEAN ADMINISTRATIVE \\ ENVIRONMENTAL DISPUTE: SEVERAL NOTES REFERRING THE \\ ENVIRONMENTAL COURTS LAW
}

Iván Hunter Ampuero*

RESUMEN: El presente trabajo tiene por finalidad responder a la pregunta acerca de la carga de la prueba en los procedimientos de reclamación ambiental en el marco de la ley 20.600, que crea los Tribunales Ambientales. Para esta finalidad se explora, en primer término, la función y extensión de la prueba en estos procedimientos jurisdiccionales, para luego exponer posibles criterios de asignación de la carga de la prueba. El autor resuelve que los criterios que podrían esgrimirse no resultan adecuados para el conflicto y complejidad de la materia. Se finaliza el trabajo postulando una regla que permita, por un lado, conjugar la presunción de la legalidad de los actos administrativos y el deber de la Administración de justificar y motivar sus decisiones; y por el otro, con la exigencia de fundamentación de la reclamación que pesa sobre el administrado.

Palabras clave: Carga de la prueba, contencioso ambiental, presunción legalidad.

ABSTRACT: This paper aims to respond to the question about the burden of proof in the environmental claim procedures according to law 20.600 which creates Environmental Courts. In order to make this aim possible, it explores the function and scope of the proof in these jurisdictional procedures. Then, it unfolds possible allocation criteria of the burden of proof. The author determines the possible criteria which may be used are not suitable to deal with the complexity and conflict gathered in this particular matter. Finally, this paper pretends to create a rule that allows, in one hand, to combine the presumption of legality of the administrative acts and the Administration's duty to justify and motivate its decisions; and, on the other hand, the motivation requirement present in every claim.

Key words: Burden of proof, environmental dispute, presumption of legality.

\section{INTRODUCCIÓN}

La ley 20.600 crea los Tribunales Ambientales (en adelante LTA) introduciendo un contencioso administrativo especializado que coloca su centro en la tutela de los derechos e intereses individuales frente a la actividad de la Administración.

Hasta el momento en nuestro país las grandes y emblemáticas controversias jurídicas en materia ambiental han sido resueltas por la justicia ordinaria. Tanto el recurso de protec-

\footnotetext{
Abogado. Licenciado en Ciencias Jurídicas y Sociales, Universidad Austral de Chile. Doctor en Derecho por la Universidad Carlos III, de Madrid, España. Profesor de Derecho Procesal U. Austral de Chile. Dirección postal: Independencia 641, Valdivia, Chile. Correo electrónico: ivanhunter@uach.cl
} 
ción, la nulidad de derecho público y ciertas reclamaciones de ilegalidad especiales (como la municipal), han servido de mecanismos jurisdiccionales de control de los actos de la Administración.

La LTA unifica -solo hasta cierto grado- las competencias para conocer de los contenciosos administrativos con incidencia ambiental, mediante dos procedimientos: el primero, denominado de "De las Reclamaciones", cuyo objetivo es revisar la legalidad de los actos dictados por la Administración, y; el segundo, llamado "Del procedimiento por daño ambiental”, que busca obtener la declaración judicial de la obligación de reparar el daño al medio ambiente. Estos procedimientos contienen una serie de reglas en materia probatoria, especialmente en relación a la admisibilidad y valoración de los medios de prueba; no obstante, la LTA no contiene ninguna disposición estableciendo reglas de la carga de la prueba. Se trata de un silencio legislativo que resulta difícil de suplir acudiendo a las reglas generales. Además genera incerteza en los ciudadanos que recurren a la tutela jurisdiccional, al abrir la posibilidad de que los Tribunales utilicen criterios disímiles u opuestos en la asignación de la carga de la prueba para un idéntico supuesto fáctico. Tampoco tenemos una experiencia acumulada en el ámbito de la jurisdicción administrativa que nos permite hacer de referente a los conflictos contenciosos ambientales.

Cuando un ciudadano, o el titular de un proyecto o actividad, quiere someter al control jurisdiccional la efectiva verificación material de los presupuestos de hecho que han habilitado la dictación de un acto administrativo, resulta relevante preguntarse acerca de la carga de la prueba, y no solo respecto de quién tiene la carga formal de probar, sino también, y con mayor importancia, quién debe soportar la falta o insuficiencia de la prueba de un hecho. Es verdad que recurrir al Art. 1698 del Código Civil puede servir para solucionar el problema de la carga de la prueba en las acciones de reparación del daño ambiental ${ }^{1}$. Esta norma se aviene muy bien a esta acción, pues quienquiera establecer la existencia de la obligación de reparar el medio ambiente deberá probarlo. Por el contrario, si el victimario quiere exonerarse de la responsabilidad tendrá que establecer su excepción en el proceso. Sin embargo, aplicar esta disposición a las reclamaciones se torna mucho más complejo, debido a la especialidad de los procedimientos administrativos ambientales.

La tesis que trataré de defender en estas líneas es que la carga de la prueba en el contencioso administrativo ambiental tiene una determinación compleja, en la medida que la decisión de adjudicar las consecuencias negativas por la falta o insuficiencia de la prueba a una de las partes, puede producir efectos perjudiciales en la satisfacción de los intereses públicos o los derechos objeto de la tutela jurisdiccional. Esto implica establecer un criterio que permita satisfacer adecuadamente esa confrontación de intereses, pero que tenga en cuenta el papel, lugar o ámbito de la prueba en la regulación específica de la LTA. En simples palabras, pretendo adaptar las construcciones procesales que han funcionado en las disputas entre particulares, a las singularidades y especificidad de las relaciones jurídicas en que interviene la Administración.

\footnotetext{
1 La remisión a esta disposición, desde luego, no escapa de las disputas que actualmente sostiene la doctrina en orden a la posibilidad de integrar las lagunas del sistema administrativo con las normas del Código Civil. Para los puntos contrapuestos, puede verse: BERMúdez (2012) pp. 62 y ss; Vergara (2010) pp. 53 y ss.
} 
Para dar respuesta a la interrogante planteada pretendo seguir el siguiente camino: (II) primero, precisar cuál es el lugar de la prueba en el contencioso administrativo, y específicamente en el contencioso administrativo ambiental diseñado con la LTA; (III) en segundo lugar, pretendo exponer algunos criterios que pudieran utilizarse al momento de distribuir las cargas probatorias, y; (IV), a continuación, quisiera proponer y justificar un criterio de carga de la prueba aplicable a las reclamaciones en contra de los actos dictados por la Administración. Finalizaré con las conclusiones (V).

\section{CUÁl ES EL ALCANCE O EL PAPEL DE LA PRUEBA EN EL CONTENCIOSO ADMINISTRATIVO AMBIENTAL}

La extensión de la prueba en el contencioso administrativo ha sido objeto de muchas y encontradas discusiones doctrinales, que caminan de la mano con la naturaleza de la jurisdicción contencioso-administrativa ${ }^{2}$. En teoría, con extrema simplificación y breve síntesis, esta cuestión puede recibir dos respuestas, por lo general, diametralmente opuestas ${ }^{3}$.

\section{PRUEBA DE LOS HeChOS EN SEDE ADMINISTRATIVA Y REVISIÓN ANTE LOS TRIBUNALES DE JUSTICIA}

Este primer modelo, que corresponde a una etapa incipiente del contencioso administrativo, postula que los hechos relevantes deben quedar probados en sede administrativa. Es en la etapa administrativa donde el ciudadano, o titular de un proyecto o actividad, debe proponer y practicar toda la prueba que estime necesaria para establecer la verdad de los hechos ${ }^{4}$. En tal situación la prueba que pueda producirse en el contencioso administrativo estaría destinada al control de la corrección o fiabilidad de las pruebas practicadas en el marco del procedimiento administrativo correspondiente. Solo in extremis correspondería admitir prueba nueva cuando la Administración haya omitido o denegado injustificadamente la práctica de algún medio probatorio 5 .

Esta clase de contencioso administrativo se acerca mucho a la apelación en materia civil, donde el tribunal se limita a efectuar un reexamen de los antecedentes probatorios y jurídicos construidos en primera instancia, y solo excepcionalmente se admite la práctica de

\footnotetext{
2 Cordón (1999) pp. 28 a 32; Fernández (1999) pp. 30 y 31, y pp. 33 a 50; García de Enterría (1989) pp. 60 a 63. Para una revisión histórica y actual del Derecho Comparado: Blanquer (2006) pp. 26 a 48.

3 Sigo en esta parte el trabajo de Borrajo (1989) pp. 127-144, en especial pp. 127 a 130. Puede verse además: Aguado I Cudolà (2013) pp. 936 a 940.

4 Vid., BarRero (2006) pp. 382 y ss, con mucha referencia jurisprudencial del derecho español.

${ }^{5}$ Esta posibilidad deja en la interrogante otra de mayor fuste: ¿Es posible suplir en sede contencioso administrativa una prueba que debió ser practicada en el procedimiento administrativo? Esta pregunta denota una de mayor amplitud relativa a la conexión entre el procedimiento administrativo y el contencioso judicial, y en especial a que sea la Administración la que supla en sede jurisdiccional la prueba que debió recabar al momento de adoptar su decisión. Vid., para una visión panorámica de este problema: BARRERO (2006) pp. 391 a 394. En Chile, reconoce Bordalí la complejidad histórica y actual de la relación entre Administración y Jurisdicción. Vid., Bordalí (2006) pp. 17 a 36, y muy especialmente, pp. 26 a 34.
} 
Hunter Ampuero, Iván — "La carga de la prueba en el contencioso administrativo ambiental chileno: ..."

prueba adicional ${ }^{6}$. De esta forma, la plenitud probatoria queda reservada al juicio de primer grado, que en este caso equivale a la instancia administrativa.

El perfil de la prueba a que apuesta este modelo es coherente con la idea de que se está revisando una decisión ya construida fáctica y jurídicamente, por lo que no es necesario aportar más antecedentes. Sin embargo, lo que está detrás de este modelo, a mi juicio, es la apuesta por un sistema de distribución de competencias basado en la deferencia entre los órganos del Estado. Según esta los órganos jurisdiccionales no debieran decidir con materiales fácticos y probatorios distintos a los considerados por la Administración al momento de dictar el acto impugnado. Ello, por la sencilla razón de que el proceso jurisdiccional solo sirve para revisar la decisión a la luz del sistema jurídico, pero no para construirla en base a nuevos o más completos antecedentes. Se trata, por tanto, de un modelo de revisión.

La LTA responde a este modelo tratándose de las reclamaciones en contra de actos de la Administración 7 . Esta ley indica las pruebas que puede utilizar el reclamante en el Art. 29 inciso $3^{\circ}$, disposición que hace aplicable las reglas del recurso de apelación civil contenidas en los artículos 186 a 230 del Código de Procedimiento Civil (en adelante CPC). De estas disposiciones, la única que se refiere a las pruebas es el Art. 207 CPC, que comienza indicando que, salvo excepciones como la del Art. 348 (prueba documental), no se admitirá en segunda instancia prueba alguna. Se complementa esta disposición con el mismo Art. 29 inciso $3^{\circ}$, que consagra una regla de inadmisibilidad probatoria para la testifical y la confesional. En consecuencia, en las acciones de reclamación no es admisible ninguna clase de prueba, sin perjuicio que la remisión a las reglas de la apelación permite entender que ante el Tribunal Ambiental el reclamante puede hacer una amplia utilización de la prueba documental (Art. 348 CPC). Así además se ha interpretado en la práctica del Primer Tribunal Ambiental.

Como una suerte de norma de clausura del sistema probatorio se consagra en el Art. 29 inciso final la posibilidad de que el Tribunal, en el plazo para dictar sentencia, decrete

\footnotetext{
6 Explica Santamaría Pastor que "la equiparación tácita del recurso contencioso con el recurso de casación civil conllevaba, entre otros efectos, que el Tribunal no podía pronunciarse sobre cuestiones que no hayan sido planteadas o resueltas en la vía administrativa previa; que en el proceso no podía practicarse más actividad probatoria que la dirigida a revisar la realizada en vía administrativa”. SANTAMARÍA (2009) p. 687 (el resaltado es nuestro).

7 A partir del modelo de contencioso administrativo que postula parte de la doctrina nacional (Bordalí (2005) p. 379) es posible cuestionar la legitimidad constitucional de un proceso que restringe a las partes considerablemente la posibilidad de proponer y practicar medios de prueba. Esto puede ser correcto, pero quizá haya que matizar esta afirmación. Hoy asistimos a un fenómeno algo ajeno a las concepciones tradicionales del proceso jurisdiccional, en la medida que las garantías del debido proceso (especialmente, del derecho de defensa) han sido situadas en el procedimiento administrativo. La exigencia de racionalidad imperada constitucionalmente para el proceso jurisdiccional queda sustituida por la racionalidad en el procedimiento de toma de decisiones al interior de la Administración. Por consiguiente, para verificar si se ha satisfecho el estándar del debido proceso, especialmente en el ámbito de las pruebas, es necesario conjugar la etapa administrativa y la jurisdiccional. Esto rompe el paradigma clásico que ha entendido que todas las garantías del debido proceso deben concurrir en la etapa judicial. La manifestación legislativa más palmaria de esta extrapolación de garantías está contenida en el Art. 18 inciso $2^{\circ}$ de la Ley Orgánica Constitucional de Bases General de Administración del Estado, que hace aplicable al procedimiento sancionatorio disciplinar el derecho a un justo y racional procedimiento. Para el derecho comparado: Comoglio (1970) pp. 217 a 222. En todo caso, lo más probable es que la constitucionalidad de este proceso termine en sede de inaplicabilidad en el Tribunal Constitucional cuando algún titular de proyecto o actividad se vea imposibilitado de generar prueba que le cause indefensión o bien cuando el Tribunal Ambiental considere que la prueba producida no le permite modificar la decisión del aparato estatal.
} 
de oficio las medidas para mejor resolver. No indica la ley cuáles pueden ser esas medidas, por lo que debemos remitirnos al Art. 159 CPC que resulta supletoriamente aplicable. Una interpretación armónica de estas disposiciones lleva a concluir que el Tribunal puede decretar de oficio todos los medios de prueba, excluyendo la confesional y la testimonial.

\section{CONTENCIOSO ADMINISTRATIVO CON PLENITUD JURISDICCIONAL.}

En esta clase de modelo, en cambio, se permite realizar un verdadero contencioso administrativo, donde la plenitud jurisdiccional, además de permitir una revisión amplia del acto de la Administración, se traduce en la posibilidad de proponer y practicar toda clase de medios probatorios. Las partes tienen absoluta libertad para proponer los medios de prueba que estimen pertinentes para acreditar los hechos que fundamentan sus pretensiones, con total independencia de si estas pruebas hayan sido denegadas u omitidas en sede jurisdiccional. Aquí, a diferencia del modelo anterior, se logra un contradictorio pleno y cabal, con un periodo de discusión y una etapa probatoria, con prescindencia de la existencia o no de actividad probatoria en sede administrativa ${ }^{8}$.

En síntesis, para este modelo se pueden aportar todos los antecedentes necesarios para construir la decisión, sin limitaciones ni en cuanto a las alegaciones ni en cuanto a la pruebas. A diferencia del sistema anterior, este no merece dudas acerca de su legitimidad en la medida que las partes que sostienen pretensiones en contra de la Administración gozan en plenitud de las garantías probatorias implícitas en el debido proceso.

La LTA responde a este modelo tratándose de la acción de reclamación por daño ambiental. En este procedimiento jurisdiccional se puede desarrollar un contencioso pleno, marcándose claramente sus etapas: un periodo de discusión (Art. 33), uno de conciliación (Art. 38), otro de prueba (Arts. 35 y 36) y luego de sentencia (Art. 43). En el aspecto probatorio se consagra como regla general la libertad de las partes para presentar todos los medios de prueba que estimen convenientes ${ }^{9}$ y la libertad de valoración probatoria conforme a la sana crítica. En un ámbito más específico, se establece la posibilidad de solicitar peritajes, de designar peritos adjuntos, e incluso de solicitar la declaración de la otra parte. La admisión de la prueba documental también es amplia y la testimonial está prevista en términos similares al actual $\mathrm{CPC}$, con la única diferencia que se permite la inclusión de testigos expertos.

No hay, sin embargo, acto administrativo previo, y no es un mecanismo de control. Las pretensiones, además, no se dirigen necesariamente contra el Estado.

\section{ALGUNOS CRITERIOS PARA DISTRIBUIR LA CARGA DE LA PRUEBA EN EL CONTENCIOSO ADMINISTRATIVO AMBIENTAL}

\section{Carga de la prueba y el contencioso administrativo ambiental en Chile}

La carga de la prueba constituye uno de los temas más interesantes del último tiempo en el Derecho Procesal Civil ${ }^{10}$. En el Derecho Comparado ha sido objeto de numerosos

\footnotetext{
8 Borrajo (1989) pp. 127 y 128.

9 El Art. 35 inciso $2^{\circ}$ primera parte LTA establece que "Serán admisibles todos los medios de prueba obtenidos por medios lícitos y que sean aptos para producir fe".

10 Fernández (2006) pp. 17 a 64 y Verde (1974) pp. 11 a 51.
} 
y profundos estudios que han logrado ir asentando ideas de cuáles son y cómo aplicarlas en las disputas de carácter patrimonial. Ese desarrollo doctrinal y jurisprudencial contrasta, sin embargo, con el estado de la disciplina en el derecho nacional, y más aún en el contencioso administrativo chileno. A la inexistencia de obras generales que se preocupen del estudio de la carga de la prueba, se añade la irrelevancia que hasta el momento ha tenido en los contenciosos administrativos ${ }^{11}$.

Las reflexiones acerca de la carga de la prueba en el contencioso administrativo ambiental debieran transitar evitando, en la mayor medida posible, dos polos: el primero, imponer al ciudadano toda la carga de probar los hechos que son materia de la impugnación a extremos en que le resulten gravosos o imposible de hacerlo. Un sistema como este corre el riesgo de perderse como tal, más aun en materia ambiental donde los actos que dicta la Administración tienen un alto contenido técnico, científico y discrecional, por lo que colocar la carga de desvirtuar los antecedentes fácticos en el reclamante puede resultar dificultoso. En segundo lugar tampoco creo razonable que el sistema jurisdiccional no asigne al recurrente algún esfuerzo probatorio o de justificación, como si se tratara de una simple revisión del acto impugnado.

El tema no parece sencillo y en teoría pueden plantearse diversas posibilidades de asignación de carga de la prueba que huyen de estos extremos, aunque no todas sean necesariamente compatibles. Quisiera, no obstante, proponer algunas alternativas que intentan ponderar las variables asociadas a la protección del medio ambiente, concentrándome exclusivamente en las reclamaciones, por ser el contencioso administrativo donde no es del todo posible extrapolar el criterio del Art. 1698 del Código Civil.

\section{Carga de la prueba COMO CARGa de la mejor información POSIBle}

El primer criterio que podría utilizarse en el ámbito de la carga de la prueba es el de la mejor información posible. Si la carga de la prueba pretende asignar a uno de los sujetos las consecuencias negativas de la falta e insuficiencia de la prueba, este efecto no es compatible con la satisfacción del interés público que supone la actividad administrativa impugnada, que es la protección del medio ambiente y la salud de las personas. Tampoco son compatibles esos efectos negativos con la debida protección de los derechos de los ciudadanos, o titulares de proyectos o actividades, que recurren a reclamar la tutela jurisdiccional.

Pareciera ser, por el contrario, que el interés público se satisface de mejor forma cuando el Tribunal Ambiental logra un conocimiento cabal y completo de los hechos, sin dudas epistémicas acerca de la verdad o falsedad de un hecho. Si esto es así, entonces la carga de la prueba en el contencioso administrativo ambiental debería recaer en aquel sujeto o parte que está en mejores condiciones de proporcionar información más completa y fiable posible ${ }^{12}$. De esta forma, lo que correspondería definir caso a caso es qué parte puede

\footnotetext{
11 Existe un último trabajo excepción a lo que aquí se ha dicho: BocKSANG (2011) pp. 217 a 243.

12 Esta podría ser una versión atenuada de la carga probatoria dinámica, o más precisamente, de los criterios de facilidad y disponibilidad probatoria. Se debe reconocer que la idea de permitir esta clase de asignación de la carga de la prueba no ha tenido muy buena recepción en el ámbito del proceso civil patrimonial (CORRAL (2012) pp. 107 a 117). Existe un temor a la utilización que puedan hacer los jueces; o más aún, hay desconfianza por el peligro de que la asignación unilateral de la carga de la prueba que formule el juez se transforme en
} 
aportar la mejor información posible de manera completa y fiable, creando un incentivo a lograr los mejores resultados probatorios. Esta regla está absolutamente conectada con el carácter epistémico que tiene la jurisdicción ${ }^{13}$, y con la necesidad de que sus decisiones se acerquen lo más posible a la realidad que pretenden regular.

En esta línea podría interpretarse el Art. 29 inciso $1^{\circ}$, primera parte, que establece la carga para el órgano público que emitió el acto impugnado de adjuntar copia autentificada del expediente administrativo completo y debidamente foliado que sirvió de base para dictar el acto que se impugna, de conformidad a lo señalado en la ley No 19.880. El razonamiento que podría estar contenido detrás de esta disposición es que si la Administración es la que puede proporcionar en el proceso jurisdiccional la información que sirve de respaldo o justificación al acto impugnado de manera más fácil y completa, entonces tiene la carga de la prueba. Esta tesis podría reforzarse con dicho por la jurisprudencia del Tribunal Supremo español, que en numerosas sentencias ha indicado que cuando la prueba e información relevante está en poder de la Administración corresponde a esta suministrarla en el juicio, puesto que de otro modo se conculcaría con su inactividad el derecho a la tutela judicial efectiva sin indefensión ${ }^{14}$.

Sin perjuicio de lo que diré más adelante estimo que esta disposición no está creando una regla de juicio, sino una especie de carga formal de aportación de prueba, o si se quiere, de exhibición documental. En efecto, al menos en el Derecho Procesal, es posible distinguir entre carga de la prueba en sentido objetivo o como regla de juicio, y carga formal de la prueba o subjetiva. Esta última pretende subrayar cuál de las partes debe aportar la prueba de un hecho específico en el curso del juicio; se trata de una carga que no está relacionada con la decisión final en caso de falta o insuficiencia de la prueba, sino con la presentación de medios de prueba para el establecimiento de un hecho específico ${ }^{15}$. La Administración tendría la carga formal de acompañar el expediente que da origen al acto administrativo, lo que no significa que deba necesariamente soportar la falta o insuficiencia de la prueba de un hecho. Otra cuestión es ponderar cuáles son las consecuencias frente al incumplimiento de esta carga de exhibición ${ }^{16}$.

una herramienta de corrección de desequilibrios sustantivos derivados de la desigualdad de las partes. Se trata, a mi juicio, de un temor infundado. Si hay algo que los jueces no hacen en nuestro país es utilizar sus poderes de oficio. En los ordenamientos que cuentan con esta posibilidad, como el español, la utilización que han efectuado los jueces ha sido bastante razonable.

13 Ferrajoli (2011) pp. 97 y ss.

14 Garrido (2002) pp. 223 y 224.

15 TARUfFo (2008) pp. 149 y 150.

16 La LTA no establece ningún tipo de consecuencia procesal al incumplimiento por parte del órgano del Estado de acompañar la copia del referido expediente administrativo. Este silencio no puede suplirse recurriendo al CPC, puesto que tampoco se hace cargo de este problema. Esto genera, a mi juicio, la necesidad de buscar algún efecto desde el punto de vista procesal, especialmente cuando el incumplimiento de esta carga puede significar la frustración de una prueba relevante para el ciudadano, o titular de un proyecto o actividad. Una posibilidad sería asignar la carga de la prueba íntegramente a la Administración, cualquiera sea el hecho que se intenta probar por medio del expediente administrativo. La otra posibilidad es aprovechar el sistema de valoración libre de la prueba para que el juez pueda construir una presunción a partir de la negativa injustificada del órgano jurisdiccional de colocar a disposición del Tribunal el expediente. Se trata, por tanto, de valorar en un sentido negativo esa conducta obstruccionista, y de darle efectos probatorios. Ormazabal (2004) pp. 54 a 62. 
A mi entender reconocerle al Tribunal Ambiental una facultad absolutamente discrecional para asignar la carga de la prueba en relación a quien pueda producir el mejor resultado probatorio, es un poder demasiado amplio, que genera incerteza ${ }^{17}$. Ahora bien, se podría justificar en contra de esta crítica que las reglas de la carga de la prueba en esta materia no son expresas, y no están lo suficientemente determinadas en el contencioso administrativo ambiental. No existiría, por lo mismo, defraudación a alguna expectativa de certeza que pueda tener el ciudadano, o el titular de un proyecto o actividad, sobre reglas que definen la decisión final. Esto es cierto. Sin embargo, este mecanismo de asignación de la carga de la prueba tiene un problema de origen: no siempre será fácil determinar cuál parte se encuentra más cerca de la prueba o la puede producir con mayor facilidad. Tampoco hay elementos para definir el momento en que debe evaluarse esa cercanía: ¿Al momento de producirse la prueba en el procedimiento administrativo o de revisarse en el proceso jurisdiccional? Se trata además de un criterio que es difícil de informar con anterioridad a la dictación de la sentencia, planteando un importante problema de inseguridad jurídica ${ }^{18}$ que solo se atenúa -pero no desaparece- por la circunstancia de que en el contencioso administrativo ambiental no se encuentra establecida de modo expreso la regla de la carga de la prueba.

\section{LA PRESUNCIÓN DE LEGALIDAD DE LOS ACTOS ADMINISTRATIVOS COMO CARGA DE LA PRUEBA}

Otra cuestión obligada en las discusiones acerca de la carga de la prueba en el contencioso administrativo es el papel que corresponde a la presunción de legalidad de los actos de la Administración. El caso nacional no es la excepción, desde que el Art. 3 inciso final de la Ley de Bases de Procedimiento Administrativo (ley, 19.880, en adelante LPA) consagró de modo expreso la presunción de legalidad de los actos de la Administración. De esta forma, los actos administrativos cuya impugnación se pretende ante el TA deben considerarse ajustados al ordenamiento jurídico. La pregunta relevante es saber si ¿tiene esta presunción de legalidad alguna repercusión en el reparto de la carga de la prueba?

En líneas generales la doctrina ha estimado que esta presunción no tiene ninguna consecuencia en relación a la carga de la prueba, y que cumpliría otra función: legitimar la exigibilidad y ejecutoriedad de los actos, junto con imponer al ciudadano la carga de impugnarlos ante los tribunales de justicia ${ }^{19}$. El ciudadano, de esta manera, tendría la carga de impugnar la validez de los actos en sede jurisdiccional, pero, en el proceso mismo la carga de la prueba no pesa necesariamente sobre el ciudadano, sino que rige íntegramente el principio de igualdad de las partes ${ }^{20}$. Parte de la doctrina explica que pretender que la

\footnotetext{
17 TARUfFo (2010) pp. 260 y ss. Las críticas de Taruffo se refieren a los sistemas jurídicos que cuentan con una regla clara de asignación de carga de la prueba, la que termina siendo modificada por el juez de acuerdo a las particularidades del caso. La crítica, por lo tanto, es parcialmente proyectable a esta materia, donde el legislador ha omitido establecer una norma de asignación de carga de la prueba en las reclamaciones.

18 En los ordenamientos en que existen estos criterios de asignación de la carga de la prueba, y que operan al momento de dictar sentencia, existe un gran consenso de que se trata de criterios excepcionales. Por todos: GONZÁLEZ (2007) pp. 58 y ss.

19 Ferrada (2007) pp. 81 y 82.

20 Entre otros: Barrero (2006) pp. 390 y 391; Aguado I Cudolà (2013) p. 940; Garrido (2002) p. 223; Bocksang (2011) p. 225. Sin embargo, también hay opiniones que disienten. Brewer Carías, ya en el año
} 
presunción de legalidad de los actos administrativos tenga implicancias en la asignación de la carga de la prueba sería infringir flagrantemente el derecho a la tutela judicial efectiva ${ }^{21}$.

Esta idea es muy común en la literatura administrativa. Sin embargo, no deja de generar algunas dudas su exactitud. La primera es que la circunstancia de que la presunción de legalidad de los actos administrativos cumpla una función extraprocesal necesaria para la eficacia de la actividad administrativa y la satisfacción de los intereses generales, no excluye la posibilidad de generar repercusiones netamente procesales. Si la ficción de validez incluye la verificación material de los antecedentes fácticos que han servido para la decisión administrativa, no se ve cómo es posible entender que esta no despliega esa fuerza en el ámbito judicial. No parece del todo razonable efectuar una separación tajante y absoluta entre lo que es efecto político o legitimador de un acto administrativo, y un efecto jurídico o probatorio.

Las presunciones legales son ficciones jurídicas que crean un estatus jurídico privilegiado a partir de la concurrencia de ciertos elementos que el ordenamiento considera valiosos. En el caso de los actos administrativos, ese estatus consiste en la asunción de su validez por la dictación a través de un procedimiento legalmente establecido. En otros términos, dado que el acto es fruto de un procedimiento que asegura los derechos de los ciudadanos, contradictorio, público, imparcial, etc., es posible afirmar su validez frente al sistema jurídico ${ }^{22}$. Por eso, cuando el ciudadano quiere impugnar jurisdiccionalmente un acto administrativo no es coherente asignarle a la Administración la carga de establecer sus presupuestos fácticos, si ello ya fue valorado, ponderado y establecido en el procedimiento administrativo. No es razonable entender que la Administración que mueve todo un aparato burocrático para la producción de una decisión que intenta integrar todas las variables ambientales, y los componentes científicos y tecnológicos, tenga que asumir la carga de probar la validez del acto así dictado.

En nuestro país una conclusión como la anterior estaría reforzada por la especialidad de los procedimientos con que se concretan las decisiones medioambientales por parte de la Administración ${ }^{23}$. Estos procedimientos están dotados de diferentes etapas que requieren un alto grado de especialización y conocimiento científico, incluyendo espacios de participación ciudadana. Son procedimientos administrativos complejos, altamente regulados y tecnificados, que pretenden integrar las variables medioambientales en la toma de decisiones. De esta forma pretende asegurarse que la decisión que adopte la Administración conjugue adecuadamente la tutela del medio ambiente con el desarrollo de actividades económicas.

Este criterio presenta algunos inconvenientes importantes como para ser utilizado en nuestro país en el contencioso administrativo ambiental. El primero es que no es capaz de

1978, explicaba que la carga de la prueba le correspondía siempre al impugnante debido a la presunción de legitimidad y legalidad de los actos administrativos, aun cuando también argumentaba que esta presunción no exoneraba a la Administración del deber de probar los hechos que respaldaban el acto dictado. BREWER (1978) pp. 24 a 52. En similar sentido, aun cuando no reconoce expresamente que la presunción de validez sea el criterio utilizado para asignarle al ciudadano la carga de probar: CHINCHILLA (1999) pp. 198 y 199.

21 Garrido (2002) p. 223.

22 Buenas razones para avalar esa conclusión pueden encontrarse en: CORDERO (2005) pp. 318 a 326.

${ }^{23} \mathrm{Al}$ menos los más importantes actos que puede ser objeto de reclamación en el contencioso administrativo ambiental son dictados luego de un procedimiento administrativo complejo y exhaustivo: RCA, normas de calidad primera y secundaria, sanciones, etc. 
dar cuenta de los actos sancionatorios donde -como veremos- es aplicable la presunción de inocencia que condiciona totalmente la asignación de la carga de la prueba. Un acto administrativo sancionatorio reclamado jurisdiccionalmente no debiera presumirse su validez, ya que ello trasladaría al ciudadano la carga de probar su inocencia.

Por otra parte, y en segundo lugar, resulta imposible reflexionar acerca de la carga de la prueba sin mirar la regulación específica del proceso jurisdiccional en la que quiere ser aplicada. En este aspecto, como ya he referido, el procedimiento judicial de reclamaciones limita ostensiblemente el campo de utilización de las pruebas, reduciéndola a la pura prueba documental. De esta manera, no me parece razonable que el ciudadano, o el titular de un proyecto o actividad, tenga la carga de desvirtuar la presunción de validez de los actos de la Administración si cuenta con un haz limitado de pruebas disponibles ${ }^{24}$. Asignar una carga sin las facultades para levantarlas puede equivaler a la indefensión ${ }^{25}$. Si se piensa, por ejemplo, en los procedimientos de evaluación de impacto ambiental en los que la Administración valora los posibles riesgos ambientales derivados de actividades o proyectos, el elemento tecnológico o científico parece asumir un rol central ${ }^{26}$. Sin embargo, la prueba pericial, que es la más idónea para discutir sobre la validez científica de los métodos utilizados o predicciones realizadas por la Administración, no resulta admisible a instancia del sujeto que reclama en sede jurisdiccional. De esta forma se produce una verdadera descompensación entre la carga de la prueba y las facultades procesales conferidas para levantarla.

\section{Principio precautorio COMO Regla de la CARGa DE la PRUEba}

Otro aspecto que parece intuitivo hacer referencia en materia ambiental cuando se habla de incerteza es el principio precautorio. Este se trata, en síntesis, que los jueces puedan resolver las dudas epistémicas aplicando como regla de juicio el principio de precaución ambiental; de esta forma si el material probatorio genera incertidumbre científica acerca de los riesgos para el medio ambiente o la salud de las personas de una actividad o proyecto, el Tribunal Ambiental pudiese adjudicar los efectos negativos de la carencia de prueba en contra de la parte que no logró despejar esa incertidumbre. Expuesto en estos términos el principio precautorio como regla de juicio tiene mucho sentido, y guarda consonancia con el ideal protector que emerge de las normas medioambientales. Ciertamente este principio inspira muchas instituciones y normas jurídicas que se adscriben a la disciplina del Derecho Ambiental, pero no es una regla de juicio que sirva para asignar la carga de la prueba.

En efecto, la doctrina estima que el principio precautorio permite a la Administración ambiental adoptar medidas y decisiones excepcionales cuando existen riesgos que amenazan

\footnotetext{
${ }^{24}$ Es necesario quizá dar cuenta que en la teoría del derecho procesal la noción de carga aparece íntimamente relacionada con la facultad procesal. Si el justiciable quiere lograr satisfacer el interés que persigue en el proceso deberá levantar las cargas procesales, cuestión que si bien no le asegura el éxito inmediato, al menos aumenta exponencialmente su exceptiva de obtener una sentencia favorable (para un análisis más detallado: FERNÁNDEZ (2006) p. 42). Sucede, no obstante, que en este proceso la posibilidad de proponer y practicar prueba se encuentra sumamente limitada y cercenada.

${ }^{25}$ La privación o limitación a la posibilidad de probar, derivada de la exclusión de ciertos medios de prueba, es una hipótesis que según Serrano Hoyos cabe perfectamente en el concepto de indefensión. SERRANO (1997) pp. 240 a 243.

${ }^{26}$ Esteve (1999) pp. 88 y 89.
} 
desmedidamente bienes o valores superiores como la salud humana o el medio ambiente, permitiendo reaccionar frente a la incerteza ${ }^{27}$. Este principio podría justificar, por ejemplo, que ante la incertidumbre acerca de los riesgos o de la tecnología aplicada en un proyecto o actividad, las consecuencias negativas de esa incertidumbre le sean adjudicadas al titular proponente. Sin embargo, la incertidumbre o los riesgos que pudieran esgrimirse por el Tribunal Ambiental para decidir las dudas epistémicas no funcionan automáticamente.

La doctrina ${ }^{28}$ entiende que la situación de incerteza requiere ser acreditada y contrastada, es decir, es necesario probar mediante informes y averiguaciones, por lo general científicas, que estamos en presencia de una situación de incerteza, donde la mejor tecnología disponible no permite establecer con un grado razonable de probabilidad los riesgos de una determinada actividad o proyecto. Se exige además que se establezca en el juicio un grado razonable de incerteza. Por tanto, no es suficiente cualquier incerteza en la producción de un riesgo, sino una que tenga la entidad suficiente como para impedir el desarrollo de alguna actividad o proyecto. Se exige un riesgo más allá de la duda científica.

Como se puede apreciar, si bien una situación de incerteza puede servir para resolver un litigio, no sirve para adjudicar la falta o insuficiencia de la prueba, desde que esta en sí requiere ser demostrada en juicio. De esta manera quienquiera valerse de la incerteza deberá probarlo en juicio. En otros términos, los jueces pueden resolver el juicio a favor del principio precautorio si llegan a la "certeza" acerca de la "incerteza" de los riesgos de una actividad, pero no porque tengan dudas si un hecho está o no probado, sino porque han logrado la convicción plena de que la mejor ciencia o tecnología disponible no asegura en un grado razonable la inocuidad para salud humana o el medio ambiente de una actividad o proyecto.

\section{LA DISTINTA CLASE DE PROCEDIMIENTOS Y ACTOS COMO MECANISMO DE ASIGNACIÓN DE LA CARGA DE LA PRUEBA}

Otro de los criterios que sería perfectamente posible de aceptar en materia contencioso ambiental, es la distribución de la carga de la prueba según la naturaleza del acto y del procedimiento administrativo ${ }^{29}$. Se trata de una clasificación y criterio que goza de mucha aceptación en el Derecho Comparado.

Así, tratándose de actos administrativos que nacen de procedimientos limitativos de derechos la carga de la prueba en la vía jurisdiccional corresponderá siempre a la Administración. Esto significa que si el ciudadano, o titular de un proyecto o actividad, incoa la tutela jurisdiccional mediante la reclamación, la Administración deberá establecer en el contencioso administrativo ambiental que los hechos materiales que han legitimado la dictación del acto son verdaderos. Cualquier carencia o insuficiencia en la prueba deberá ser asumida por la Administración, en el sentido que se producirá la invalidez del acto por no concurrir un elemento fáctico que ha justificado su dictación. Este criterio puede hacerse extensivo a los actos que restringen o modifican un derecho o statu quo. En el campo específico del derecho nacional este criterio debería operar en las solicitudes de medidas

\footnotetext{
27 Esteve (2004) p. 212.

28 Esteve (2004) p. 204 y Martínez (2004) pp. 368 y 369.

29 Barrero (2006) pp. 192 y ss; Blanquer (2006) pp. 218 y ss; BreWer (1978) pp. 29 y ss.
} 
provisionales que efectúe la Superintendencia de Medio Ambiente; la reclamación del Art. 25 quinquies LBGMA cuando se pretende modificar una RCA por cambios en las variables contempladas y evaluadas en el Plan de Seguimiento.

Es una condición mínima de racionalidad del ejercicio del poder estatal, especialmente en el campo de las potestades discrecionales, imponer a la Administración la carga de demostrar mediante información completa y fiable, la verdad de los supuestos fácticos que la han movido a dictar actos que amaguen derechos de los titulares de proyecto o actividades. Si en la revisión jurisdiccional se produce alguna duda o incerteza respecto de algún hecho, las consecuencias desfavorables deberán ser soportadas por la Administración. Por ejemplo, si hay dudas acerca de la variación de las variables ambientales evaluadas y contempladas en el plan de seguimiento, el acto administrativo que modifica la RCA quedará sin efecto, puesto que la carga de acreditar tal circunstancia, que es modificativa o limitativa de un derecho, corresponde a la Administración.

Esta misma tesis es aplicable a las reclamaciones judiciales de los actos que se dictan como consecuencia de procedimientos sancionatorios y cuyo conocimiento también le corresponde a los Tribunales Ambientales en virtud del Art. $17 \mathrm{~N}^{\circ} 6$ LTA. La carga de la prueba le corresponderá siempre a la Administración, porque se entiende que hace ejercicio del ius puniendi del Estado ${ }^{30}$. Hay un consenso sistemático en la doctrina de que en estos casos rige la presunción de inocencia, asumiendo la Administración la carga de producir prueba válida y contradictoria para establecer la responsabilidad del titular del proyecto o actividad $^{31}$. Aquí, al igual que en materia penal, la presunción de inocencia sirve de regla de juicio, adjudicando las consecuencias negativas de la falta o insuficiencia de la prueba al órgano sancionador. Por lo general, la prueba que justifica la aplicación de una sanción se producirá en el ámbito del procedimiento administrativo que da origen al acto sancionador, en el que el ciudadano, o titular de un proyecto o actividad, tienen asignados amplias posibilidades de defensa ${ }^{32}$.

En cambio, y por otra parte, si la impugnación se refiere a actos de autorización ambiental, corresponderá al titular del proyecto o actividad acreditar en el proceso que se cumplen con los requisitos previstos en las normas jurídicas que permiten a la Administración conceder el permiso correspondiente. La asignación al titular del proyecto o actividad de la carga de la prueba es consustancial a la idea de que se derivarán consecuencias jurídicas favorables si demuestra que su iniciativa cumple con la normativa ambiental pertinente. A la vez puede estimarse como una carga mínima para quien desea desarrollar actividades económicas que pueden generar impactos negativos al medio ambiente o a la salud de las personas.

Por dos razones, estos criterios de asignación de la carga de la prueba que han sido utilizados en los procedimientos administrativos no resultan del todo aplicables. Una de

\footnotetext{
30 Bermúdez (2013) p. 427.

31 Nieto (2012) pp. 370 y ss; Coвo (2008) p. 60, y Aguado I Cudolà (2001) pp. 95 y ss.

$32 \mathrm{El}$ procedimiento sancionatorio en materia ambiental se encuentra contenido desde los artículos 47 a 54 de la Ley 20.417, complementado con los artículos 55 y 56 referido a los recursos administrativos y jurisdiccionales. En este procedimiento se contempla la posibilidad de una efectiva defensa del presunto infractor: ser notificado de la denuncia; posibilidad de efectuar descargos; solicitar las medidas probatorias que resulten pertinentes y conducentes, entre otros.
} 
esas razones tiene una connotación teórica y la otra práctica. Las actividades o proyectos susceptibles de producir efectos ambientales negativos están sujetos a un control público preventivo que se concentra en la fórmula de las autorizaciones. En teoría no es tan claro que las autorizaciones administrativas tengan la calidad de creadoras de derechos. En realidad, la doctrina identifica a las autorizaciones como un mecanismo de limitación administrativa $^{33}$, y ciertamente lo puede ser si se considera a la libertad para desarrollar una actividad empresarial como un derecho subjetivo público ${ }^{34}$. La exigencia de autorización previa viene a constituir una restricción o limitación al ejercicio de un derecho, y en ese sentido podría reconducirse al primer criterio de asignación de la carga de la prueba.

En segundo lugar, estos criterios están pensados para actos que admiten una clasificación binaria. Cuando un acto administrativo es o de gravamen o creador de derechos, será fácil aplicar estos criterios. Pero esta bifurcación no siempre se produce. Sucede que en el Derecho Ambiental hay muchos actos difíciles de clasificar en algunas de estas categorías. Quizá el más importante de todos, la RCA, tiene ese problema. Esta tiene una naturaleza compleja, puesto que junto con permitir el desarrollo de un proyecto o actividad, somete al titular a una serie de cargas y obligaciones, como son las condiciones o exigencias ambientales, o las medidas de mitigación, compensación o reparación, generando un vínculo permanente entre la Administración y el titular del proyecto o actividad ${ }^{35}$. El permiso o autorización para desarrollar una actividad empresarial se encuentra estrechamente vinculada con las cargas, medidas o condiciones que la Administración solicita al titular para la ejecución de un proyecto o actividad, por lo que resulta imposible separarlos o modificarlos. Puede decirse lo mismo respecto de los actos normativos ambientales, cuya naturaleza cuesta definir, aun cuando pueden estimarse más cercanos a los actos de gravamen en la medida que posibilitan el establecimiento de limitaciones al desarrollo de actividades económicas.

\section{HACIA UNA PROPUESTA DE REGLA DE CARGA DE LA PRUEBA EN LAS RECLAMACIONES AMBIENTALES ${ }^{36}$}

1. Carga de justificación de los actos de la administración COMO CARGa de la PRUEBA

La tesis que he pretendido esbozar es que la carga de la prueba en las reclamaciones ambientales se identifica con la carga de justificación de los actos que le corresponde a la

\footnotetext{
33 Vera (1994) pp. 72 y 136, y García de Enterría (2004) pp. 108 y ss.

34 Acerca del alcance y sentido de la garantía constitucional: FernANDOIs (2011) pp. 117 y ss.

35 García de Enterría y Fernández (2004) p. 142, y Sepúlveda (2012) pp. 24 y ss.

36 La pregunta en cuestión deja al margen quizá una de mayor relevancia como es el estándar de prueba exigible en los contenciosos ambientales. La pregunta del estándar de prueba dice relación con la suficiencia de la información para tener por acreditado un hecho en el juicio, y en consecuencia, definir el margen de error que se está dispuesto a tolerar en la decisión de un hecho. En materia penal y civil patrimonial, es posible entender cierto consenso respecto de cuál es el estándar aplicable: la duda razonable en el primero y la probabilidad preponderante, en el otro. En materia contencioso administrativa, sin embargo, no hay estudios específicos que puedan proporcionar algunas luces, sin perjuicio de entender que la contraposición entre el interés general y el individual podrá servir de referencia al momento de establecer la suficiencia de prueba. Vid., al respecto en el Derecho comparado: PARDO (2013) pp. 99 a 118, y en el Derecho chileno: ACCATino (2011) pp. 483 a 511, y en especial, pp. 484 a 489.
} 
Administración. Para esta hipótesis es esencial arrancar de dos circunstancias: la primera, es que la presunción de legalidad del acto administrativo traslada al ciudadano, o titular de un proyecto o actividad, la carga de impugnarlo ante los tribunales de justicia, mediante la interposición de una reclamación. La carga, sin embargo, no se levanta con la sola interposición de la reclamación sino que es necesario fundamentarla. Esta es una exigencia expresamente contemplada en el Art. 27 LTA $^{37}$, al establecer que la reclamación deba contener los fundamentos de hecho y de derecho en que se apoya. La segunda, es que la Administración en general, y en especial en materia ambiental, tiene el expreso deber de justificar sus decisiones. Este deber se desprende de los artículos 11 inciso $2^{\circ}$ y 41 inciso $4^{\circ} \mathrm{LPA}$; de los artículos 9, 15 bis, 16, 18 bis, 20, 29, 30 bis y 30 ter de la LBGMA; de los artículos 3 letras i) y j), 47 inciso final, 48 y muy especialmente el Art. 54 de la Ley Orgánica de la Superintendencia de Medio Ambiente. Este deber de justificación ha tenido un abundante reconocimiento jurisprudencial incluso antes de la entrada en vigencia de la $\mathrm{LPA}^{38}$, y se encuentra muy enraizado como mecanismo de control de la actividad del Estado.

Esta postura es conciliable con el peso de la tradición jurídica del Derecho Administrativo, en el sentido de entender que la presunción de legalidad de los actos de la Administración no tiene efectos probatorios, y en ese sentido, no sirve como regla de juicio. Pero también con la forma en que debe funcionar la revisión de los actos administrativos y con una distribución razonable de las funciones procesales.

\section{VEROSIMILITUd Y JUSTIFICACIÓN DEL ACTO}

Si un acto dictado por la Administración no goza de una presunción de legalidad con efectos probatorios, es evidente que tampoco puede presumirse la verdad de su contenido material. En consecuencia, el establecimiento de los hechos que han justificado la dictación del acto, y que constituyen el presupuesto fáctico de la norma aplicada por la Administración, deberían ser acreditados en juicio asumiendo esta el riesgo probatorio. Esta podría ser una conclusión analíticamente perfecta, pero requiere ser matizada ¿es posible ignorar completamente que los actos de la Administración son dictados en un procedimiento administrativo que asegura la disputa de intereses contrapuestos y la participación del interesado o afectado?

A mi entender resulta difícil prescindir de la forma en que se producen los actos en sede administrativa, y que, en último término, son los órganos del Estado los que adoptan

\footnotetext{
37 Esta disposición establece: "De la reclamación. Toda reclamación se presentará por escrito, y en ella se indicarán sus fundamentos de hecho y de derecho y las peticiones concretas que se someten a la resolución del Tribunal. Este examinará en cuenta si la reclamación ha sido interpuesta en tiempo y forma. Podrá declararla inadmisible mediante resolución fundada si, en opinión unánime de sus miembros, no hubiere sido interpuesta dentro de plazo, se refiera a materias que estén manifiestamente fuera de su competencia, no esté debidamente fundada o no contenga peticiones concretas. Esta resolución podrá impugnarse, mediante reposición con apelación subsidiaria, dentro de quinto día de notificada”.

38 Sentencia de la Corte de Apelaciones de Concepción, de 18 de octubre de 2005, recaída en recurso de protección, Sánchez con Secretaría Regional Ministerial del Servicio de Salud VIII Región; Sentencia de la Corte de Apelaciones de Punta Arenas, de 16 de abril de 1996, recaída en reclamo de ilegalidad municipal, Rol N 7970, y; sentencia de la Corte de Apelaciones de Santiago, de 4 de julio de 2008, recaída en recurso de reclamación, Rol: 8273-07,
} 
la decisión en un procedimiento público, transparente e imparcial, tratando de satisfacer los intereses generales. De esta forma, si bien es posible negar la presunción de veracidad de los hechos que justifican la dictación y el contenido de un acto administrativo, al menos es posible afirmar que gozan de una verosimilitud o apariencia de verdad ${ }^{39}$ que requiere ser desvirtuada o puesta en duda con la impugnación. La presencia de etapas y elementos de cognición, especialmente las pruebas y el contradictorio que se produce al interior de la Administración, permiten otorgarle al acto esa apariencia de verdad que no alcanza a justificar una presunción de verdad, pero somete al ciudadano a ciertas exigencias o cargas al momento de impugnar el acto.

En efecto, el ciudadano, o titular de un proyecto o actividad, además de la carga de impugnación, deberá justificar su reclamación en términos de desvirtuar la verosimilitud o credibilidad del acto administrativo. Si esto es así, es decir, si la impugnación permite desvirtuar esa verosimilitud o apariencia de verdad, entonces la carga de justificar la decisión es de la Administración. Esta es una carga absolutamente coherente con la idea de que los actos que dicta la Administración requieren de la genuina verificación de los hechos que permiten ejercer la potestad pública ${ }^{40}$. Por consiguiente, si en el procedimiento jurisdiccional no se logra probar los hechos que justifican la decisión, el aparato administrativo deberá asumir las consecuencias negativas de esa falta o insuficiencia probatoria. Por el contrario, si el ciudadano no logra con la fundamentación de su impugnación desvirtuar o poner en duda la credibilidad del acto, entonces asumirá íntegramente la carga de la prueba, y las consecuencias negativas de la duda serán asumidas por él.

Este criterio se identifica con las consideraciones que anteriormente destaque como esenciales: por un lado, la carga de fundamentar la impugnación que corresponde al recurrente. El ciudadano, o titular de un proyecto o actividad, que recurre al Tribunal Ambiental asumirá una carga de impugnación y justificación de su reclamación, con la finalidad de destruir la apariencia de verdad del acto administrativo. Para ello, lo más probable, es que encamine su pretensión intentando demostrar que los antecedentes disponibles en sede administrativa no justifican la decisión de la Administración. Esto, ciertamente, permite colocar de manifiesto que no resulta admisible una simple revisión jurisdiccional de los actos administrativos, sin justificación del interesado.

A lo anterior se debe agregar que el ciudadano, o el titular de un proyecto o actividad, deberá justificar en sede jurisdiccional las circunstancias fácticas legitimantes para lograr el éxito de su pretensión impugnatoria, como son la afectación o el perjuicio derivado de la dictación del acto administrativo (Art. 18 LTA). Esto implica, en simples palabras,

\footnotetext{
39 Asumo que en el ámbito del Derecho Procesal (o de la epistemología jurídica) el concepto de verosimilitud no es muy pacífico y tampoco ha sido aceptado cuando su finalidad es reemplazar a la noción de verdad procesal. Este término hace referencia a la apariencia de verdad que se le asigna a una afirmación fáctica cuando parece refrendada por el estado normal en el devenir de las cosas. TARUfFo (2009) pp. 183 y ss. También puede consultarse: Monereo (2006) pp. 33 a 39. En ambos casos hay una facilitación en la prueba que beneficia a la Administración, pero que no alcanza a justificar una inversión total de la carga de la prueba. Verosimilitud es un estándar inferior a prueba completa.

40 Para ejemplos jurisprudenciales: Soто (2012) pp. 432 a 436.
} 
que el reclamante corre con la carga de acreditar estas circunstancias de manera que la falta o insuficiencia de la prueba deberá asumirlas íntegramente.

El segundo criterio al que permite responder esta fórmula de asignación de la carga de la prueba es al deber de justificación de los actos de la Administración. Esta es una exigencia que se conecta con la idea misma de la función administrativa. Las decisiones que produce la Administración, en tanto persiguen la consecución de los intereses públicos o generales, requieren una justificación en la realidad. Y es que el ejercicio de una potestad finalizada que no tiene sustento fáctico, además de arbitraria e ilegal, no está satisfaciendo el interés público. En este sentido, es un verdadero incentivo a que las decisiones administrativas estén epistémicamente justificadas, el que el aparato burocrático tenga que asumir los riesgos de la falta o insuficiencia probatoria de esa justificación en el campo jurisdiccional.

Este criterio es una exigencia de racionalidad en el ejercicio del poder, especialmente si consideramos los amplios espacios de apreciación técnica y discrecional con que resuelve la Administración en materia ambiental ${ }^{41}$. Pero además se aumentan las probabilidades de que se produzcan decisiones administrativas acertadas y aceptables que satisfagan de mejor forma el interés general.

\section{La posición institucional del Tribunal Ambiental como JUSTificación de la} CARGA DE LA PRUEBA

Puede parecer extraño que para justificar -en los términos que más arriba se ha desarrollado- la asignación de la carga de la prueba a la Administración se tenga que recurrir a una razón más política o ideológica que de otra naturaleza, como la posición del Tribunal Ambiental en la institucionalidad ambiental de nuestro país. Y es que resulta imposible olvidar que el Tribunal Ambiental ha sido concebido como un contrapeso al aumento de las potestades legales y discrecionales de la Administración en materia ambiental ${ }^{42}$. Muy en

41 Cordero (2005) p. 340.

42 GuZMán (2012) pp. 230 y ss. Este punto queda magníficamente explicado en el Mensaje con que el Ejecutivo despachó al Congreso el Proyecto de Ley que crea los Tribunales Ambientales, que indica expresamente lo siguiente: "existen buenas razones para promover la potestad administrativa de sanción desde la perspectiva de la calidad regulatoria y la eficiencia de los sistemas de cumplimientos, pero eso no se puede hacer a cualquier precio (...) Por otro lado, existen buenas razones para acotar las potestades de los organismos administrativos en defensa de los derechos de los particulares, pero eso no puede significar afectar el interés público y el bienestar social detrás de la regulación (...) Por tal motivo, los sistemas democráticos han tratado de buscar equilibrios. Por un lado, dotando a los organismos administrativos de competencias regulatorias y de sanción, que busquen una finalidad de disuasión efectiva (y no una retributiva) para promover cumplimientos y por la otra, establecer un mecanismo efectivo de revisión judicial de las intervenciones de las autoridades públicas (...) Los jueces cumplen un rol esencial en el sistema de contrapesos de un sistema democrático, pero también tienen un rol esencial e insustituible en la protección de los derechos de las personas. Es decir, actúan como instrumentos al servicio de la democracia para limitar los desbordes del poder público, en especial de la Administración en relación a las competencias conferidas por el legislador, y por la otra, como instrumento al servicio de la tutela de derechos, ahí donde la exigencia de tutela efectiva resulta indispensable (...) Esto explica por qué resulta necesario crear un tribunal, pero concretamente el de un tribunal especializado. Medio Ambiente es un buen espacio para conjugar ese equilibrio. En él está en juego el bienestar de la comunidad, pero también el derecho de personas específicas que puedan verse afectadas por las decisiones de la autoridad pública (...) Por tal motivo el Ejecutivo ha accedido a la creación de un Tribunal Ambiental, pero en el contexto de un acceso a una tutela judicial efectiva por parte de los ciudadanos en estas materias, de modo de no restringir su competencia solo al 
concreto, el Tribunal Ambiental surge como un garante de los derechos de los ciudadanos, o de los titulares de proyectos o actividades, frente a las potestades administrativas de regulación, gestión, fiscalización y sanción.

Se trata de un órgano que viene a establecer un equilibrio entre la intensidad de la actividad administrativa, justificada en la protección del medio ambiente como derecho constitucional, y la necesidad de asegurar una tutela rápida, eficaz y, por sobre todo, especializada, para el evento de producirse una vulneración de derechos o intereses legítimos. Este órgano jurisdiccional si bien no va a conocer de todas los conflictos con incidencia ambiental ${ }^{43}$, al menos permitirá a los titulares de proyectos o actividades reclamar una tutela especializada y rápida, para un conflicto de ribetes complejos y que demanda un alto grado de componentes técnicos y científicos.

Si este es el sentido de la creación de los Tribunales Ambientales no resulta lógico que en el procedimiento de reclamación la carga de la prueba se le asigne íntegramente al ciudadano, o el titular de proyecto o actividad, de manera que las consecuencias negativas de la falta o insuficiencia de la prueba deban asumirlas estos. Dicho en otras palabras, si los Tribunales Ambientales pretenden hacer frente a la lesión de derechos por parte de la Administración, siguiendo un proceso establecido legalmente, carece de todo sentido entender que los afectados deben soportar la duda de la prueba de los hechos, a la vez que la Administración, como parte del contencioso, no asuma carga de ninguna especie. Un genuino y efectivo contrapeso no se alcanza adjudicando al administrado la carga de probar los hechos que desvirtúen la decisión administrativa, más aun si consideramos que la posibilidad de que los reclamantes puedan aportar prueba se encuentra muy limitada ${ }^{44}$.

Este análisis apunta en el sentido indicado anteriormente. Una buena forma de racionalizar el ejercicio de las potestades estatales en el ámbito ambiental -y por ende, del

control de las decisiones de la Superintendencia, sino que también ampliarlo a todo el contencioso de la Ley No 19.300, permitiendo de ese modo, el igual acceso a la jurisdicción a todos los ciudadanos".

${ }^{43}$ El Art. 17 LTA establece el catálogo de competencias que serán de conocimiento del Tribunal Ambiental. Hay muchas competencias que no serán conocidas por este tribunal, como por ejemplo, la solicitud de invalidación de la resolución de calificación ambiental que aprueba un proyecto o actividad, o la solicitud de invalidación de una norma primaria o secundaria cuando se fundamente en una causal distinta a la de ser contraria a la ley 19.300. Para estos casos subsistirán la nulidad de derecho público, y por cierto, el recurso de protección.

${ }^{44}$ Este podría ser un motivo muy relevante al momento de justificar un rol activo del tribunal en la recopilación de las pruebas relevantes. La modalidad que asume la LTA para actividad probatoria ex officio son las medidas para mejor resolver. No puede dejar de llamar la atención la opción del legislador, francamente en desuso y con un desprestigio a nivel mundial. Las medidas para mejor resolver representan uno de los momentos más primitivos de la actividad probatoria del juez, y su origen se remonta, según algunos autores, a las Partidas de Alfonso X el Sabio; por ende, su extensión se hizo presente en casi los códigos de corte clásico que siguieron el modelo español de 1881, no así en los modelos kleinianos que reconocieron al juez la potestad de aportar prueba en la denominada audiencia preliminar. Esto, desde luego, tuvo una explicación muy clara. El estilo del proceso medieval común que ilustró el sistema procesal hispano del siglo XIX y parte del XX, supuso la figura de un juez completamente aislado de la contienda, solo atento a decidir el conflicto jurídico al final de todos los trámites. En este sentido, prácticamente en el único momento en que el juez entraba en contacto directo con el "expediente" y revisa las pruebas practicadas es en la etapa final del procedimiento, de manera que solo en ese momento le es posible determinar la existencia de algún hecho en duda o simplemente verificar la carencia del material probatorio. De ahí que la doctrina haya dicho con justa razón que "son poderes que están pensados para un juez que no dirige materialmente el proceso y que actúa de espectador hasta el último momento". CORTés y Moreno (2004) p. 474. 
ejercicio del poder del Estado- es dándole a la Administración la carga de probar la justificación de sus actos.

\section{CONCLUSIONES}

La ley 20.600 que crea los Tribunales Ambientales introduce un procedimiento jurisdiccional de revisión de los actos dictados por la Administración con incidencia en alguno de los instrumentos de gestión ambiental. En este proceso contencioso administrativo no existe ninguna disposición que haga referencia a las reglas de la carga de la prueba, y tratándose de las reclamaciones no resulta muy fácil aplicar la norma del Art. 1698 del Código Civil. Esto justifica la necesidad de encontrar alguna regla que permita conjugar adecuadamente los diferentes intereses que se envuelven en el conflicto, y que además tenga presente la regulación de la prueba en esta sede jurisdiccional. En este sentido, el papel de la prueba es bastante residual en la medida que los reclamantantes podrán hacer uso, casi exclusivamente, de la prueba documental. El Tribunal Ambiental deberá limitarse a valorar la prueba y los antecedentes producidos en el procedimiento administrativo, y solo excepcionalmente permitirá la producción de prueba nueva o adicional.

En teoría es posible postular diversos criterios para asignar la carga de la prueba, los que, sin embargo, presentan distintos problemas que impiden su utilización en forma general. Algunos de ellos, como el de la mejor información posible, tienen un sustento que simpatiza con el carácter cognoscitivo de la jurisdicción, y tiende a generar mejores resultados probatorios. Pero no es lo suficientemente determinado como para generar una certeza y seguridad en los que recurren a la tutela jurisdiccional. Otros, en cambio, se avienen muy bien con el carácter protector de las normas medioambientales como el principio precautorio. Aun así, la duda o incerteza respecto del riesgo de una actividad o proyecto requiere ser justificada (probada) más allá de la duda científica. El otro criterio que funciona bien es el de la presunción de legalidad del acto administrativo. No obstante, hay consenso en la doctrina que esta presunción no tiene efectos probatorios. Por último, se podría utilizar un criterio afín con la naturaleza de los actos que se producen en materia ambiental, pero este no funciona del todo, pues atendida la naturaleza de la disciplina los actos que dicta la administración no son fácilmente clasificables en una categoría.

Frente a lo anterior parece razonable postular una regla que tenga presente varias razones. La primera es que el Tribunal Ambiental está concebido como un mecanismo de contrapeso al aumento de las potestades de la Administración en la materia. La segunda es que la facultad de aportar prueba en los procedimientos jurisdiccionales de reclamación está sumamente limitada. La tercera es que la Administración se somete a una serie de reglas que deberían asegurar la justicia y razonabilidad de la decisión. Y la cuarta es que la Administración tiene el imperativo de justificar sus decisiones en materia ambiental. De estas consideraciones es posible concluir que la carga de la prueba le corresponderá a la Administración, la que tiene que probar la justificación del acto dictado, siempre y cuando el reclamante haya desvirtuado por medio de los fundamentos de la impugnación la verosimilitud o apariencia de verdad que emana del acto administrativo. 


\section{BIBLIOGRAFÍA CITADA}

Accatino, Daniela (2011): “Certezas, dudas y propuestas en torno al estándar de prueba en materia penal" Revista de Derecho de la Pontificia Universidad Católica de Valparaíso, vol. XXXVII, Nº 2: pp. 483-511.

Aguado I Cudolà, Vincec (2001): “La prueba en el procedimiento sancionador" Justicia Administrativa Revista de Derecho Administrativo, Número Extraordinario: pp. 93-114.

Aguado I Cudolà, Vincec (2013): "La prueba en el proceso contencioso-administrativo: ¿Supletoriedad de la legislación procesal civil o necesidad de una regulación específica?, Justicia contenciosa administrativa (México, Instituto de Investigaciones Jurídica Universidad Nacional Autónoma de México) pp. 935-954.

Barrero Rodríguez, Concepción (2006): La prueba en el procedimiento administrativo (Madrid, Thomson Aranzadi).

BERMúdeZ, Jorge (2012): Las relaciones entre el derecho administrativo y el derecho común. Derecho positivo. Doctrina y jurisprudencia (Santiago, Thomson Reuters).

BERMúdEZ, Jorge (2013): "Fundamento y límites de la potestad administrativa sancionadora en materia ambiental”, Revista de Derecho de la Pontificia Universidad Católica de Valparaíso, vol. XL, N¹: pp. 421-447.

Blanquer, David (2006): La prueba y el control de los hechos por la jurisdicción contenciosoadministrativa (Valencia, Tirant lo Blanch).

Bocksang Hola, Gabriel (2011): "La carga de la prueba de la nulidad de un acto administrativo", en Arancibia, Martínez y Romero (Coords.) Litigación Pública (Santiago, Thomson Reuters) pp. 217-243.

Bordalí, Andrés (2005): "Principios de una nueva justicia administrativa en Chile", Ferrada Bórquez, Juan Carlos (Coord.), Justicia Administrativa (Santiago, Editorial LexisNexis) pp. 341-381.

Bordalí, Andrés (2006): "La Administración Pública ante los Tribunales de Justicia Chilenos”, Revista Chilena de Derecho, vol. 33, N 1: pp. 17-36.

Borrajo Iniesta, Ignacio (1989): "Prueba y jurisdicción revisora", Revista Española de Derecho Administrativo, $\mathrm{N}^{\circ}$ 61: pp. 127-144.

Brewer Carías, Allan (1978): "La carga de la prueba en el Derecho Administrativo", Revista Centro de Estudios de Filosofía del Derecho, vol. 23: pp. 24 a 52.

Chinchilla, Carmen (1999): La desviación de poder (Madrid, Civitas).

Сobo Olvera, Tomás (2008): El procedimiento administrativo sancionador (Barcelona, Editorial Bosch).

Comoglio, Luigi (1970): La garanzia costituzionale dell' azione ed il processo civile (Padova, Cedam).

Cordero Vega, Luis (2005): "Procedimiento administrativo y la jurisdicción contencioso administrativa”, en Ferrada Bórquez, Juan Carlos (Coord.), Justicia Administrativa (Santiago, Editorial LexisNexis) pp. 301-340.

Cordón Moreno, Faustino (1999): El proceso contencioso-administrativo. Conforme a la Ley 29/1998, de 13 de julio, reguladora de la Jurisdicción Contencioso-Administrativa (Pamplona, Editorial Aranzadi) 
Corral, Hernán (2012): "Sobre la carga de la prueba en el proyecto de Código Procesal Civil”, en Aguirrezabal, Maite (editor), Justicia Civil: perspectivas para una reforma en la legislación chilena (Santiago, Universidad de los Andes) Cuadernos de Extensión, № 23, pp. 107-117.

Cortés Domínguez, Valentín y Moreno Catena, Víctor (2004): Derecho Procesal Civil Parte General (Valencia, Tirant lo Blanch).

Esteve Pardo, José (2004): "La operatividad del principio de precaución en materia ambiental" El principio de precaución y de su proyección en el Derecho administrativo español, CGPJ, N²6: pp. 197-214.

Esteve Pardo, José (1999): Técnica, riesgo, y Derecho. Tratamiento del riesgo tecnológico en el Derecho ambiental (Barcelona, Ariel).

FERnÁNdez López, Mercedes (2006): La carga de la prueba en la práctica judicial civil (Madrid, Editorial La Ley).

FERNÁNDEZ TORRES, Juan Ramón (1999): Jurisdicción administrativa revisora y tutela judicial efectiva (Madrid, Editorial Civitas).

Fernandois, Arturo (2011): Derecho constitucional económico. Garantías económicas, doctrina y jurisprudencia (Santiago, Ediciones Universidad Católica de Chile).

FERradA, Juan Carlos (2007): "Potestades y privilegios de la Administración en el régimen administrativo chileno" Revista de Derecho de la Universidad Austral de Chile, vol. 20, $\mathrm{N}^{\circ}$ 2, pp. 64-94.

Ferrajoli, Luigi, (2011): "El papel de la función judicial en el Estado de derecho" en Carbonell, Orozco y Vázquez (Coords.), Jurisdicción y argumentación en el Estado Constitucional de Derecho (México, Universidad Autónoma de México) pp. 87-108.

García de Enterría, Eduardo (1989): Hacia una nueva justicia administrativa (Madrid, Civitas).

García de Enterría, Eduardo y Fernández, Tomás-Ramón (2004): Curso de Derecho Administrativo, Tomo II (Madrid, Thomson Civitas).

Garrido Falla, Fernando (2002): Tratado de Derecho Administrativo. La Justicia Administrativa, Vol. III (Madrid, Tecnos).

González Granda, Piedad (2007): "Los criterios de disponibilidad y facilidad probatoria del artículo 217 de la LEC”, Carga de la prueba y responsabilidad civil (Valencia, Tirant lo Blanch) pp. 29-74.

Guzmán Rosen, Rodrigo (2012): Derecho ambiental chileno. Principios, instituciones, instrumentos de gestión (Santiago, Editorial Planeta Sostenible).

Martínez de Velasco, Joaquín (2004): "El control judicial del principio de precaución. ¿Control jurisdiccional de la incertidumbre?” El principio de precaución y de su proyección en el Derecho administrativo español, CGPJ, N²6, 2004: pp. 361-398.

Monereo Pérez, José Luis (2006): La carga de la prueba en los despidos lesivos de derechos fundamentales (Valencia, Tirant lo Blanch).

Nieto, Alejandro (2012): Derecho Administrativo Sancionador (Madrid, Tecnos).

Ormazabal, Guillermo (2004): Carga de la prueba y sociedad de riesgo (Madrid, Marcial Pons). 
PARdo, Michael (2013): “Estándares de prueba y teoría de la prueba” en Vázquez, Carmen (ed.), Estándares de prueba y prueba cientifica, Ensayos de epistemología jurídica (Madrid, Marcial Pons).

Santamaría Pastor, Juan (2009): Principios de Derecho Administrativo General, Tomo II, (Madrid, Iustel).

Sepúlveda Solar, Doris (2012): Invalidación sobreviniente. El caso de la resolución de calificación ambiental, (Santiago, AbeledoPerrot-LegalPublishing).

Serrano Hoyos, Gregorio (1997): La prohibición de indefensión y su incidencia en el proceso (Granada, Editorial Comares).

Sото KLoss, Eduardo (2012): Derecho administrativo. Temas fundamentales (Santiago, LegalPublishing).

TARUfFo, Michele (2009): La prueba de los hechos (Madrid, Editorial Trotta).

TARuffo, Michele (2008): La prueba (Madrid, Marcial Pons)

TARUffo, Michele (2010): Simplemente la verdad. El juez y la reconstrucción de los hechos (Madrid, Marcial Pons).

Vera Jurado, Diego (1994): La disciplina ambiental de las actividades industriales (Madrid, Editorial Tecnos).

VERDE, Giovanni (1974): L'onore della prova nel processo civile (Nápoles, Jovene Editore).

Vergara Blanco, Alejandro (2010): El derecho administrativo como sistema autónomo. El mito del Código Civil como "derecho común" (Santiago, AbeledoPerrot-LegalPublishing).

\section{JURISPRUDENCIA CITADA}

Sánchez con Secretaría Regional Ministerial del Servicio de Salud VIII Región: Corte de Apelaciones de Concepción, 18 de octubre de 2005, recurso de protección.

Empresa Magallánica Industrial y Comercial S.A. con Municipalidad de Punta Arenas: Corte de Apelaciones de Punta Arenas, 16 de abril de 1996, Reclamo de ilegalidad municipal, Rol N 7970 .

Bestpharma S.A. con Central de Abastecimiento del Sistema Nacional de Servicio de Salud: Corte de Apelaciones de Santiago, 4 de julio de 2008, Recurso de reclamación, Rol $\mathrm{N}^{\circ} 8273-07$.

\section{NORMAS LEGALES CITADAS}

Ley $\mathrm{N}^{\circ}$ 20.600, del 28 de junio de 2012, que crea los Tribunales Ambientales.

Ley $\mathrm{N}^{\circ}$ 19.300, de 9 de marzo de 1994, sobre Bases Generales del Medio Ambiente y su modificación por la ley 20.473, de 13 de noviembre de 2010 .

Ley $\mathrm{N}^{\circ}$ 18.880, del 29 de mayo de 2003, que establece Bases de los Procedimientos Administrativos que Rigen los actos de los órganos de la Administración del Estado. 
